\title{
DISCRIMINAÇÃO SALARIAL DE GÊNERO E A PERCEPÇÃO DOS AGENTES: ANÁLISE NA PROFISSÃO DE CONTROLLER
}

\section{GENDER WAGE DISCRIMINATION AND AGENT PERCEPTION: ANALYSIS IN THE CONTROLLER PROFESSION}

\author{
MARCIA ZANIEVICZ SILVA \\ Universidade Regional de Blumenau. Endereço: Rua Antônio da Veiga, $140 \mid$ \\ Itoupava Seca | 89030-903 | Blumenau/SC | Brasil. \\ (1) http://orcid.org/0000-0003-1229-7705 \\ marciaza@gmail.com
}

\section{ALICE CAROLINA AMES}

Universidade Regional de Blumenau. Endereço: Rua Antônio da Veiga, $140 \mid$ Itoupava Seca | 89030-903 | Blumenau/SC | Brasil.

(1) http://orcid.org/0000-0002-7612-6094

aliceames@hotmail.com

\section{MIKAÉLI DA SILVA GIORDANI}

Universidade Regional de Blumenau. Endereço: Rua Antônio da Veiga, $140 \mid$ Itoupava Seca | 89030-903 | Blumenau/SC | Brasil. (D) http://orcid.org/0000-0002-4871-7858

mikagiordani@hotmail.com

\section{RESUMO}

O estudo objetivou evidenciar aspectos de discriminação salarial de gênero na atuação de controllers e descrever, por meio do discurso dos agentes, como estes percebem as práticas discriminatórias. Para tanto, realizou-se uma pesquisa exploratória, com abordagem mista. A população abrangeu os profissionais controllers do Brasil com perfis ativos na rede de contatos profissionais LinkedIn ${ }^{\circledR}$ no ano de 2018. Os dados foram coletados por meio de questionários e entrevistas com profissionais. Para análise quantitativa foi realizado o Teste de Levene e o Teste $T$ de Student e para análise qualitativa dos dados foi utilizado a análise do discurso. Destaca-se que a discriminação de gênero foi percebida na profissão de controller, por meio das dificuldades em relação ao exercício da profissão, que envolvem aspectos como carga horário e assédio sexual. As contribuições que esta pesquisa apresenta se referem a profissão e a percepção dos agentes frente a desigualdades. Ainda, para organizações, os resultados podem sinalizar reflexões para mudanças e até mesmo estimular outras empresas a fortalecerem a equidade entre homens e mulheres.

Palavras-chave: Discriminação salarial. Gênero. Profissão de Controller. 


\begin{abstract}
The study aimed to highlight aspects of gender wage discrimination in the performance of controllers and describe, through the discourse of agents, how they perceive discriminatory practices. To this end, an exploratory research with a mixed approach was performed. The population comprised Brazil's professional controllers with active profiles on the LinkedIn ${ }^{\circledR}$ professional network in 2018. Data were collected through questionnaires and interviews with professionals. For quantitative analysis, the Levene Test and the Student T Test were performed, and for the qualitative analysis of the date, speech analysis was used. It is noteworthy that gender discrimination was perceived in the controller profession, through the difficulties related to the practice of the profession, which involves aspects such as workload and sexual harassment. The contributions presented by this research refer to the profession and the agents' perception of inequalities. However, for organizations, the results can signal reflections on change and even spur other companies to strengthen equity between men and women.
\end{abstract}

Keywords: Wage discrimination. Genre. Profession of Controller.

\title{
1 INTRODUÇÃO
}

A existência de desigualdade salarial entre homens e mulheres ainda é fato no mundo moderno. Conforme Pettit \& Hook (2002), o aumento das taxas de participação do trabalho feminino no mercado não é suficiente para suprimir a desigualdade, evidencia-se que em diferentes países, os homens continuam a receber remuneração significativamente maior que as mulheres. Adicionalmente, existe a segregação ocupacional, na qual o mercado de trabalho direciona as mulheres para ocupações tradicionalmente feminizadas (Madalozzo, 2010).

No contexto da profissão contábil, dada a ascensão da contabilidade global, a profissão possui papel relevante na manutenção de ideologias (Farjaudon \& Morales, 2013), além de fornecer assessoria, regulação de sistemas contábeis e demonstrações. No que diz respeito às mulheres na área contábil brasileira, apesar de representarem $43 \%$ dos registros ativos (Conselho Federal de Contabilidade, 2019), as desigualdades permanecem. Deste modo, alguns estudos buscaram evidenciar desigualdade de gênero no campo de atuação contábil.

Brighenti, Jacomossi e Silva (2015) destacaram que há desigualdade de gênero no contexto contábil Catarinense. Silva (2016) aponta que existem barreiras simbólicas que impossibilitam ascensão das mulheres em altos cargos na hierarquia organizacional. Haussmann Vogt, Hein e Silva (2018) afirmam que há desigualdade de gênero na atuação de profissionais Administradores, Contadores e Economistas. Já Dal Magro, Carpes, Vergini e Silva (2018) evidenciaram que barreiras para a ascensão feminina aos níveis hierárquicos mais altos reduz o desempenho das empresas. Nesse sentido, verifica-se que as mulheres estão fazendo parte de processos e mudanças na profissão contábil, o que demonstra a influência das mesmas na área (Haynes, 2017), no entanto, como observado em Dwyer e Roberts (2004), sem haver equidade de gênero na atuação profissional.

Dentre as diversas possiblidades de atuação dos contadores e oportunidades de progresso na carreira, a função de controller tem se destacado. Segundo Lunkes, Schnorrenberger, Gasparetto e Vicente (2009), a controladoria está relacionada a diversas atividades dentro da organização, desde emissão de relatórios, controle e planejamento até tomada de decisões. Dentre os requisitos para o desempenho da função de controller, estudos tem indicado: atuar proativamente (Weber, 2011), ter formação, principalmente em contabilidade (Gomes, Souza \& Lunkes, 2014), possuir conhecimento de outro idioma e domínio de diferentes áreas administrativas (Wiggers, Lunkes \& Souza, 2015).

Diversas pesquisas têm dedicado atenção aos aspectos de desigualdade entre homens e mulheres perante o mercado de trabalho. No contexto internacional, cita-se por exemplo o estudo 
de Whiting e Wright (2001), que analisou o estado de equidade de gênero da profissão contábil; Dambrin e Lambert (2012) que propôs uma reflexão quanto à raridade de mulheres em níveis hierárquicos superiores na contabilidade; Flynn, Earlie e Cross (2015) cujo objetivo foi examinar as percepções de contadores masculinos e femininos sobre a progressão na carreira feminina na profissão de contabilidade; e Haynes (2017) que, através de uma revisão da literatura, verificou que nos últimos 25 anos a posição das mulheres na contabilidade evoluiu bastante, mas que ainda existem desafios na profissão tanto para mulheres quanto para homens em vários níveis.

No âmbito nacional, Brighenti et al. (2015) buscaram evidências de desigualdade de gênero na atuação de contadores e auditores no mercado de trabalho; Silva (2016) investigou a trajetória acadêmica em contabilidade das mulheres brasileiras negras, em relação às interações cotidianas, sexualização e racialização; Bernd, Anzilago e Beuren (2017) verificaram a presença de mulheres entre discentes de programas de pós-graduação em Ciências Contábeis; Haussmann et al. (2018) analisaram aspectos que evidenciassem a desigualdade de gênero na atuação de profissionais da área de Ciências Sociais Aplicadas; Dal Magro et al. (2018) identificaram o glass ceiling em níveis hierárquicos mais altos e o impacto disso no desempenho das organizações.

Embora o mundo tenha mudado para as mulheres nos últimos anos, as quais avançaram no desenvolvimento de sua presença na profissão contábil (Haynes, 2017), a desigualdade permanece e, por essa razão, a questão do gênero continua relevante (Broadbent \& Kirkham, 2008). Nessa perspectiva, observa-se carência quanto à investigação da desigualdade salarial por gênero no mercado de trabalho, especificamente na profissão de controller, uma função contemporânea, de prestígio e que emana poder nas organizações, sendo relevante a realização de uma pesquisa com abordagem mista, a fim de ampliar as evidências e as discussões sobre o tema.

Nesse contexto, apresenta-se a seguinte questão norteadora de pesquisa: quais aspectos evidenciam e descrevem a desigualdade de gênero na atuação dos controllers? Diante disso, o objetivo do estudo é evidenciar aspectos de desigualdade de gênero na atuação de controllers e descrever, por meio do discurso dos agentes, como estes percebem as práticas discriminatórias.

Embora a temática de desigualdade de gênero tenha uma agenda consolidada, tanto no contexto acadêmico quanto na sociedade organizada, ainda há muito a ser discutido e investigado empiricamente. $\mathrm{O}$ estudo justifica-se pela necessidade de realizar pesquisas reflexivas sobre gênero como sinal de luta contínua para melhorar a posição da representação feminina na profissão contábil (Dambrin \& Lambert, 2012). Justifica-se também pois, conforme Haynes (2017), em diferentes economias e partes do mundo há diferenças no papel da contabilidade e da desigualdade de gênero, fato que reafirma a necessidade de desenvolver mais pesquisas sobre a interação entre contabilidade e gênero para que se possa verificar diferentes insights, especificamente sobre a desigualdade.

Ressalta-se que estudos anteriores evidenciaram a discriminação salarial na profissão contábil, porém em sua maioria abordam a temática com base em dados exclusivamente quantitativos ou qualitativos, o presente estudo difere-se dos demais pois, além de evidenciar a desigualdade com base em dados quantitativos, busca compreender por meio do discurso dos agentes as razões envolvidas no contexto da discriminação salarial de gênero. Além disso, como mencionado por Carnegie e Lehman (2012), novas áreas de investigação sobre o tema, como a profissão de controller, são essenciais, para contestar a repressão e a discriminação e promover a justiça social.

O artigo está estruturado em cinco seções, incluindo esta introdução. A próxima seção corresponde ao referencial teórico que fundamenta o estudo. A terceira seção apresenta os aspectos metodológicos realizados na pesquisa. Em seguida, têm-se a análise dos dados e por fim é apresentada a conclusão desta pesquisa. 


\section{REFERENCIAL TEÓRICO}

No referencial teórico abordou-se inicialmente aspectos relacionados a função do controller. Na sequência, trata-se da desigualdade salarial de gênero e estudos anteriores nos quais se expõe a temática a fim de maior suporte e embasamento para o presente estudo.

\subsection{A Função de Controller}

Os profissionais controllers, conforme Weber (2011), são vistos como responsáveis por diversas funções, tendo como papel central fornecer informações aos tomadores de decisão, como também outras tarefas relacionadas a cooperação com os gerentes, por exemplo envolvimento de forma proativa na gestão da organização. Nesse contexto, os funcionários, gestores e proprietários das organizações são considerados agentes econômicos racionais, responsáveis pelos processos e pela tomada de decisões (Guerreiro, Frezatti \& Casado, 2006).

Atualmente há uma expectativa em relação aos controllers para que sejam competentes em usarem seus conhecimentos, habilidades e experiências, para que as informações da contabilidade juntamente com informações não financeiras sejam integradas, também que sejam capazes de entender, justificar e demonstrar resultados para a organização como um todo, e em seus departamentos (Král, Mikołajewicz, Šoljaková \& Nowicki, 2017).

Nesse contexto, com a rápida mudança no ambiente de negócios, as condições em que as empresas operam são afetadas, portanto é necessário desenvolver habilidades ligadas a ações estratégicas. Montano, Donoso, Hassall e Joyce (2001) evidenciaram que as instituições de ensino superior devem abordar no currículo habilidades e tópicos de conhecimento em contabilidade gerencial. Empregadores consideram relevante habilidades de comunicação e controle do estresse, assim, esses aspectos devem ser desenvolvidos de forma integrada com os tópicos do conhecimento.

Em decorrência do ambiente competitivo, as empresas necessitam de planejamento, controle e gestão de suas atividades, nesse meio o controller apresenta-se diretamente envolvido no processo decisório (Zoni \& Kenneth, 2007). Verifica-se que o controller deixou de ser o profissional "contador de feijão", o qual dedicava-se às funções tradicionais e reativas, e passou a ocupar uma posição de "parceiro de negócios", ao atuar de forma proativa e estratégica no processo organizacional e tomada de decisões (Weber, 2011). Entretanto, ressalta-se que a função pode variar entre organizações, sendo que o tamanho e a estrutura são fatores que definem como esse profissional atuará (Oro, Beuren \& Carpes, 2013).

Dessa forma, o controller pode exercer diversas funções, tais como planejamento, controle, contábil e sistemas de informações (Lunkes et al., 2009). Nesse sentido, o estudo de Gomes et al. (2014) identificou o perfil do profissional solicitado por empresas brasileiras. Os resultados evidenciaram que o mercado de trabalho procura controllers com formação principalmente em Ciências Contábeis, com conhecimento em tecnologia da informação e contabilidade internacional. Além disso, destacam a participação de forma sistêmica na gestão, com liderança, proatividade e capacidade analítica.

Wiggers et al. (2015) observaram que as organizações utilizam como requisito para contratação do controller, ter conhecimento de outro idioma, bem como domínio em auditoria, tributação, finanças, economia, sistema de informação e de tecnologia. Os autores constatam que em empresas brasileiras a função de parceiro de negócios ainda não está consolidada, prevalecendo o controller "contador de feijão", focado em atribuições técnicas e que geralmente recebe salários mais baixos se comparado ao parceiro de negócios.

Nesse sentido, torna-se essencial a qualificação dos profissionais da área contábil, com a finalidade de aprimorar as habilidades e competências constantemente, de modo a atender às demandas do mercado. As empresas possuem exigências distintas para a contratação de profissionais para a função, sendo que diversos fatores podem ser considerados, como o tipo e 
porte da empresa, o segmento de atuação e a localização geográfica (Gomes et al., 2014). Do exposto, constata-se que as atividades realizadas pelos controllers e os atributos para atuar na função, segundo descrito nos estudos supracitados, não implicam em barreiras de entrada para homens ou mulheres. No entanto, evidências advindas de outras áreas de atuação dos contadores, por exemplo, administração, economia e auditoria (Haussmann et al., 2018; Brighenti et al., 2015) sugerem que o sexo do profissional na função de controller pode ser um fator de distinção. Nesse caso, seria um fator discriminatório, difícil constatação explícita, geralmente sutilmente percebido por aquelas que vivenciam ou vivenciaram seus reflexos.

\subsection{Desigualdade Salarial de Gênero}

A discriminação no mercado de trabalho por gênero pode ser visualizada em praticamente todas as sociedades (Araújo \& Ribeiro, 2001). Logo que o termo gênero significa uma construção social e cultural, que se relaciona diretamente com o significado de ser homem ou mulher na sociedade (Haynes, 2013). Nessa linha, assim como as pessoas, ocupações e atividades também possuem identidades de gênero. Scott (1987) relata que as identidades de gênero correspondem a atividades, instituições e organizações sociais, em todos os níveis da sociedade, as quais podem ser construídas e reconstruídas, e que não dependem das pessoas físicas que a praticam, apesar de possuírem relação. Esse conceito de gênero evidencia a necessidade de compreender quando e como a identidade de gênero, como a da profissão contábil, foi constituída e reconstituída.

Historicamente, a participação feminina no mercado de trabalho foi seletivamente permitida, as ocupações para as mulheres residiam em uma esfera doméstica, cuja escolaridade era combinada com a experiência de casa (Kirkham \& Loft, 1993). Na contabilidade, o cenário observado são hierarquias profissionais que tendem a permanecer firmes ao sexo, com preponderância masculina em níveis seniores, apesar dos esforços de algumas empresas de contabilidade para direcionar políticas de apoio às mulheres (Broadbent \& Kirkham, 2008). E ainda, conforme Lehman (1992), no início do século XX, os conflitos de gênero estavam voltados ao acesso das mulheres na profissão contábil. Kirkham (1992), ao analisar a opressão das mulheres na contabilidade, acrescenta uma dimensão política que aborda a inter-relação do desenvolvimento da profissão, ao relacionar o poder e a influência da profissão em termos de gênero. A profissão contábil no princípio foi conceituada como uma prática masculina, pois as características exigidas para o exercício da profissão contrastavam com a imagem da mulher. Entretanto as mulheres ingressaram na profissão, porém as funções desempenhadas inicialmente eram limitadas a escrituração e algumas práticas administrativas (Kirkham \& Loft, 1993).

Ao analisar as desigualdades de gênero na remuneração, consideram-se as diferenças entre homens e mulheres em termos de qualificação e as diferenças do tratamento de ambos quando partilham da mesma função. Tanto as habilidades como as qualificações são fatores específicos de gênero que influenciam na disparidade salarial (Blau \& Kahn, 1994). Evidencia-se que a disparidade salarial entre homens e mulheres existe desde a entrada das mulheres no mercado de trabalho, mesmo quando mulheres e homens são equivalentes em termos de idade, tipo de agregado familiar, qualificações, experiência e etnia (Whiting \& Wright, 2001).

A discriminação é muitas vezes assumida como o único fator para explicar as desigualdades entre homens e mulheres no emprego remunerado (Burke, 1994). O envolvimento das mulheres na força de trabalho remunerado é, em grande parte, uma resposta aos custos e benefícios do trabalho assalariado. Ainda, o aumento da participação da mulher no emprego formal pode ser atribuído, pelo menos em parte, a mudanças estruturais da economia, que influenciam a demanda e a oferta de trabalhos femininos (Pettit \& Hook, 2002).

Hofstede (1991) descreveu que os comportamentos masculinos e femininos são diferentes na sociedade. Em uma sociedade com elevado índice de masculinidade é propícia a existência de trabalhos que valorizam o sucesso e progresso material, são ambientes que enfatizam a competição entre os membros. Por sua vez, nas sociedades com características de feminilidade valoriza-se a igualdade, solidariedade e qualidade de vida no trabalho. Neste sentido, o estudo de Whiting \& 
Wright (2001) relata que as mulheres consideram as responsabilidades familiares ao ingressar no trabalho. Sendo que, as mulheres aceitam empregos com salários mais baixos, localizados perto do lar, a fim de ter horários de trabalho compatíveis às demandas domésticas e educação dos filhos.

A segregação profissional generalizada, que distingue o trabalho masculino do feminino, orienta muitas mulheres para o trabalho remunerado inferior, em ocupações pouco ou não qualificadas (Bradley, 1999). Conforme Marlow \& Carter (2004), existe uma considerável resistência das associações profissionais e de seus membros quanto ao ingresso da mulher no trabalho, no entanto, evidencia-se que as mulheres conquistaram ocupações até então dominadas por homens e, teoricamente, estão em igualdade com a contraparte masculina. Assim, as mulheres passam a reivindicar um emprego altamente recompensado e, lentamente, alteram a visão tradicional do papel fêmeo no mercado de trabalho.

Estudos como o de Haussmann et al. (2018) analisam aspectos que constatam a desigualdade de gênero em profissionais da área de Ciências Sociais Aplicadas no mercado de trabalho brasileiro. Os resultados apontaram que há desigualdade de gênero em relação a profissão de Administrador, Contador e Economista. Já Brighenti et al. (2015) buscou investigar evidências quanto a desigualdade de gênero de contadores e auditores no mercado de trabalho brasileiro, especificamente no estado de Santa Catarina, os autores concluíram que há desigualdade de gênero na atuação de homens e mulheres no contexto contábil catarinense, assim como na remuneração, mesmo que os profissionais tenham mesmo nível de escolaridade.

Logo, apesar das mulheres se inserirem em diferentes composições em termos de classe, raça e idade e se envolverem em uma ampla variedade de trabalhos e ocupações, como um grupo social, estão sujeitas a diferentes graus de subordinação associado ao gênero, o que consequentemente gera um impacto negativo em sua experiência de trabalho assalariado (Marlow \& Carter, 2004). Nesse sentido, os estudos supracitados indicam que ser mulher afeta criticamente o acesso de uma pessoa ao mercado de trabalho e a progressão da carreira.

As evidências apesentadas indicam que por mais que haja programas e esforços para mitigar esse fato, a segregação de gênero ainda está presente no mercado de trabalho. Nesse contexto, destaca-se que a profissão contábil é moldada e influenciada por pressões econômicas e sociais mais amplas que se inter-relacionam para gerar a subordinação feminina em geral. Essas desvantagens vivenciadas pelas mulheres significam, em geral, que esse grupo é capaz de acumular menos capital financeiro, social e cultural com sua experiência no trabalho assalariado quando comparada ao gênero oposto (Marlow \& Carter, 2004). Isto posto, faz-se necessário ampliar as discussões e pesquisas, de maneira a contribuir com a modificação do status quo predominante.

\section{METODOLOGIA}

Conforme a problemática do estudo e alinhado ao objetivo proposto, a pesquisa adota uma abordagem quanti-qualitativa. Por meio do método quantitativo busca-se evidências estatisticamente significativas sobre a ocorrência de desigualdade salarial e, pelo método qualitativo analisa-se o discurso de profissionais para ampliar a compressão de aspectos da desigualdade presentes no cotidiano a atividade de controller.

Salienta-se a importância de esclarecer o uso das palavras 'sexo' e 'gênero' utilizados neste estudo. O conceito de sexo é essencialmente voltado à diferença biológica, entre homem e mulher (Haynes, 2017), enquanto o gênero é o efeito de definições sociais, culturais e internalizações do significado de ser homem ou mulher (Haynes, 2013). Assim, o gênero como conceito tende a direcionar a atenção para a diversidade de corpos e explorar as noções existentes de feminino e masculino (Young, 2013). Dessa forma, embora, conceitualmente exista diferenças entre os termos sexo e gênero, no presente estudo, por uma questão de estrutura e articulação do texto, usa-se a palavra gênero para distinguir homens e mulheres, haja vista que, não foi possível incorporar ao estudo outros gêneros. 
Os dados quantitativos para análise da desigualdade salarial de gênero foram coletados por meio de questionários, enviados aos controllers via LinkedIn®. Sendo que receberam um link para acesso ao questionário, desenvolvido no aplicativo eletrônico do Microsoft Forms e teve como base as informações requeridas pelo Cadastro Geral de Empregados e Desempregados (Caged). O questionário possibilita comparar dados específicos da atividade de controller com os obtidos por Haussmann et al. (2018) e Brighenti et al. (2015), os quais utilizaram a base do Caged.

A opção em utilizar um instrumento de coleta de dados e não as informações disponibilizadas nas bases nacionais, como o cadastro geral de empregados, decorre do fato destas bases de dados não evidenciarem informações exclusivas à função de controller. Sendo assim, esta pesquisa buscou dados dos respondentes referente ao sexo, faixa etária, raça e cor, deficiência, grau de instrução, data de admissão, faixa salarial e carga horária semanal. Além dessas informações também foi solicitado aos entrevistados o segmento e o número de funcionários da empresa ao qual estão vinculados. O período de envio dos questionários compreendeu de setembro de 2018 até janeiro de 2019, também foram enviados convites para cerca de 400 profissionais localizados em todas as regiões do país, dos quais 135 retornaram, constituindo-se a amostra da pesquisa.

A Tabela 1 apresenta a caracterização da amostra, segregada pelo nível hierárquico do cargo de controller, setor e o tamanho da empresa (medido pelo número de funcionários).

Tabela 1

\section{Características da amostra}

\begin{tabular}{l|r|r|l|r|r|l|c|c}
\hline Cargo & $\mathbf{n}_{\boldsymbol{i}}$ & \multicolumn{1}{c|}{$\mathbf{P}_{\boldsymbol{i}}$} & Setor & \multicolumn{1}{c|}{$\mathbf{n}_{\boldsymbol{i}}$} & \multicolumn{1}{c|}{$\mathbf{P}_{\boldsymbol{i}}$} & Tamanho & $\mathbf{n}_{\boldsymbol{i}}$ & $\mathbf{P}_{\boldsymbol{i}}$ \\
\hline Coordenação & 14 & $10,37 \%$ & Comércio & 15 & $11,11 \%$ & De 1 a 49 & 25 & $18,52 \%$ \\
\hline Diretoria & 27 & $20 \%$ & Ensino & 1 & $0,74 \%$ & De 50 a 99 & 15 & $11,11 \%$ \\
\hline Gerência & 74 & $54,81 \%$ & Indústria & 56 & $41,48 \%$ & De 100 a 249 & 33 & $24,44 \%$ \\
\hline Supervisão & 5 & $3,70 \%$ & Serviços & 46 & $34,07 \%$ & De 250 a 499 & 17 & $12,60 \%$ \\
\hline Staff & 8 & $5,93 \%$ & Transporte & 3 & $2,22 \%$ & De 500 a 999 & 15 & $11,11 \%$ \\
\hline Outros & 7 & $5,19 \%$ & Outros & 14 & $10,38 \%$ & 1000 ou mais & 30 & $22,22 \%$ \\
\hline Total & $\mathbf{1 3 5}$ & $\mathbf{1 0 0 \%}$ & & $\mathbf{1 3 5}$ & $\mathbf{1 0 0 \%}$ & & $\mathbf{1 3 5}$ & $\mathbf{1 0 0 \%}$ \\
\hline
\end{tabular}

Fonte: Dados da pesquisa.

Observa-se a predominância no nível de atuação do profissional controller na Gerência, o que pode ser relevante no que tange ao profissional ter conhecimento sobre todos níveis da empresa e a gerenciá-los. Também, quanto ao setor de atuação, os destaques são respectivamente para o setor de Indústria e Serviços. Nessa perspectiva, as características da amostra destacam que há um maior número de controllers atuando na gerência e no setor da indústria em empresas de grande porte. A amostra está alinhada com o estudo de Weber (2011) ao evidenciar uma diversidade de níveis hierárquicos na função de controllers.

Quanto à análise qualitativa, para descrever a percepção dos agentes em relação a desigualdade salarial de gênero, foram novamente enviados convites aos profissionais controllers, convidando-os para uma segunda etapa de pesquisa, realizada por entrevista. O roteiro de entrevista (Apêndice 1) contemplou oito questões abertas e, até o momento, foram entrevistados quatro profissionais, dois homens e duas mulheres. Ressalta-se que os entrevistados, atuam em empresas de grande porte, ou seja, com 1000 ou mais funcionários. Em decorrência da localização geográfica dos envolvidos, as entrevistas foram feitas pelo software Skype, sendo gravadas e posteriormente transcritas.

No que se refere à análise dos dados, para os dados quantitativos foi realizado o Teste de Levene e o Teste t de Student no software SPSS Statistics 23, cujo objetivo foi verificar a variância e diferença estatística, respectivamente, em relação aos aspetos dos controllers dos sexos masculino e feminino. Por sua vez, para análise qualitativa dos dados foi utilizado a análise de discurso. Essa técnica assume que em todo discurso há um significado que pode ser compreendido através de análise apropriada (Bauer \& Gaskell, 2015). 


\section{APRESENTAÇÃO E ANÁLISE DOS RESULTADOS}

$\mathrm{Na}$ apresentação e análise dos resultados apresenta-se primeiramente a análise quantitativa dos achados, a qual corresponde aos dados oriundos do questionário. Posteriormente, apresentase os dados provenientes das entrevistas realizadas com profissionais controllers.

Inicialmente apresenta-se a estatística descritiva das variáveis, que contempla o Teste de Levene e o Teste $\mathrm{t}$ de Student, a fim de verificar se há diferenças significativas entre aspectos referentes a profissionais controllers do sexo masculino e feminino. Realizou-se o Teste de Levene para igualdade de variâncias, o qual avalia se os dados do grupo do sexo masculino e feminino são ou não homogêneos. Os resultados mostraram que existe uma igualdade de variâncias dos grupos, em relação as variáveis idade, grau de instrução e benefícios, pois a significância apresentou-se superior a $0,05(\mathrm{p}>0,05)$. Entretanto com relação a variável faixa salarial o teste não apresentou variância homogênea $(\mathrm{p}<0,05)$ entre os grupos.

A Tabela 2 apresenta a média, desvio padrão das variáveis por grupo (masculino e feminino) e amostra total, também exibe o Teste de Média t de Student.

Tabela 2

Estatística descritiva das variáveis

\begin{tabular}{|c|c|c|c|c|c|c|c|c|}
\hline & \multicolumn{6}{|c|}{ Estatística Descritiva } & \multirow{2}{*}{\multicolumn{2}{|c|}{$\begin{array}{c}\text { Teste de Média } \\
\text { (t de Student; bi- } \\
\text { caudal) }\end{array}$}} \\
\hline & \multicolumn{2}{|c|}{ Sexo Masculino (83) } & \multicolumn{2}{|c|}{ Sexo Feminino (52) } & \multicolumn{2}{|c|}{ Amostra Total } & & \\
\hline & Média & $\begin{array}{l}\text { Desvio } \\
\text { Padrão } \\
\end{array}$ & Média & $\begin{array}{l}\text { Desvio } \\
\text { Padrão } \\
\end{array}$ & Média & $\begin{array}{l}\text { Desvio } \\
\text { Padrão } \\
\end{array}$ & $\mathbf{T}$ & Sig. \\
\hline Idade & 38,939 & 8,211 & 36,352 & 6,677 & 37,859 & 7,792 & 1,896 & $0,060 *$ \\
\hline Grau Instrução & 3,939 & 0,591 & 3,823 & 0,555 & 3,896 & 0,576 & 1,130 & 0,260 \\
\hline Faixa Salarial & 4,036 & 1,152 & 3,549 & 1,404 & 3,837 & 1,276 & 2,083 & 0,040 ** \\
\hline Benefícios & 6,337 & 2,868 & 5,451 & 2,941 & 6,007 & 2,907 & 1,720 & $0,088^{*}$ \\
\hline
\end{tabular}

Nota. Níveis de significância: * $\mathrm{p}<0,1, * * \mathrm{p}<0,05, * * * \mathrm{p}<0,01$

Fonte: Dados da pesquisa.

Das quatro variáveis que foram objeto do teste de médias, três delas apresentaram variações significativas quando comparadas entre profissionais de sexos distintos, com nível de significância de $5 \%$ e $10 \%$. Somente a variável grau de instrução não demonstrou diferença estatisticamente significante entre os grupos. Para a variável idade, o grupo masculino apresentou em média, idade superior ao grupo do sexo feminino. Dessa forma, pode-se inferir que os homens que ocupam cargos de controllers possuem idade maior que as mulheres nesse cargo. No entanto a diferença de médias para essa variável foi significativa ao nível de $10 \%$.

Em relação a faixa salarial, verifica-se que o grupo do sexo masculino em média está na faixa 4, a qual refere-se à remuneração entre 10 e 12 salários mínimos, diferente do grupo feminino o qual a média apresenta-se na faixa 3, que corresponde a uma remuneração entre sete e nove salários mínimos. Observa-se que as mulheres possuem remuneração inferior aos homens no cargo estudado. Essa variável apresentou diferença de médias significativa ao nível de 5\%. Esse resultado está de acordo com o evidenciado anteriormente por Dal Magro et al. (2018), Haussmann et al. (2018) e Brighenti et al. (2015) que relataram desigualdade de remuneração entre indivíduos com o mesmo cargo, na área contábil, porém em outras funções. Dessa forma constata-se no presente estudo que essa desigualdade persiste também para a função de controller. Ainda, cabe destacar, em relação a amostra total, que 59 dos respondentes possuem remuneração correspondente a mais de 12 salários mínimos, entretanto a média geral apresenta-se na faixa salarial três (7 a 9 salários mínimos).

Tratando-se da variável benefícios, a qual corresponde aos benefícios oferecidos pela empresa, o grupo do sexo masculino apresentou valores superiores ao grupo do sexo feminino, seis e cinco benefícios, respectivamente. Dentre os benefícios mais citados estão, alimentação (89\%), assistência médica (87\%) e assistência odontológica (67\%), em contrapartida, o benefício menos citado foi auxílio creche $(10 \%)$. 
Conforme evidenciado, a variável grau de instrução não apresentou diferença de média estatisticamente significativa entre os grupos, o que indica que homens e mulheres que ocupam o cargo de controller possuem grau de instrução semelhantes. A média geral foi de 3,896, o que indica que em média os respondentes possuem especialização, mais especificamente $74 \%$ da amostra total. Também foi constado que as áreas de formação acadêmica de maior concentração dos respondentes foi Ciências Contábeis (62\%) e Administração (28\%). Esse achado apresenta-se em conformidade com o estudo de Gomes et al. (2014) o qual identificou que as empresas brasileiras procuram principalmente profissionais controllers com formação em contabilidade.

Adicionalmente, foi questionado aos respondentes sobre as habilidades requeridas para o cargo. A Figura 1 apresenta as nuvens de palavras com as habilidades mencionadas pelos respondentes, sendo que a primeira se refere as habilidades citadas pelas mulheres e a segunda as habilidades citadas pelos homens.
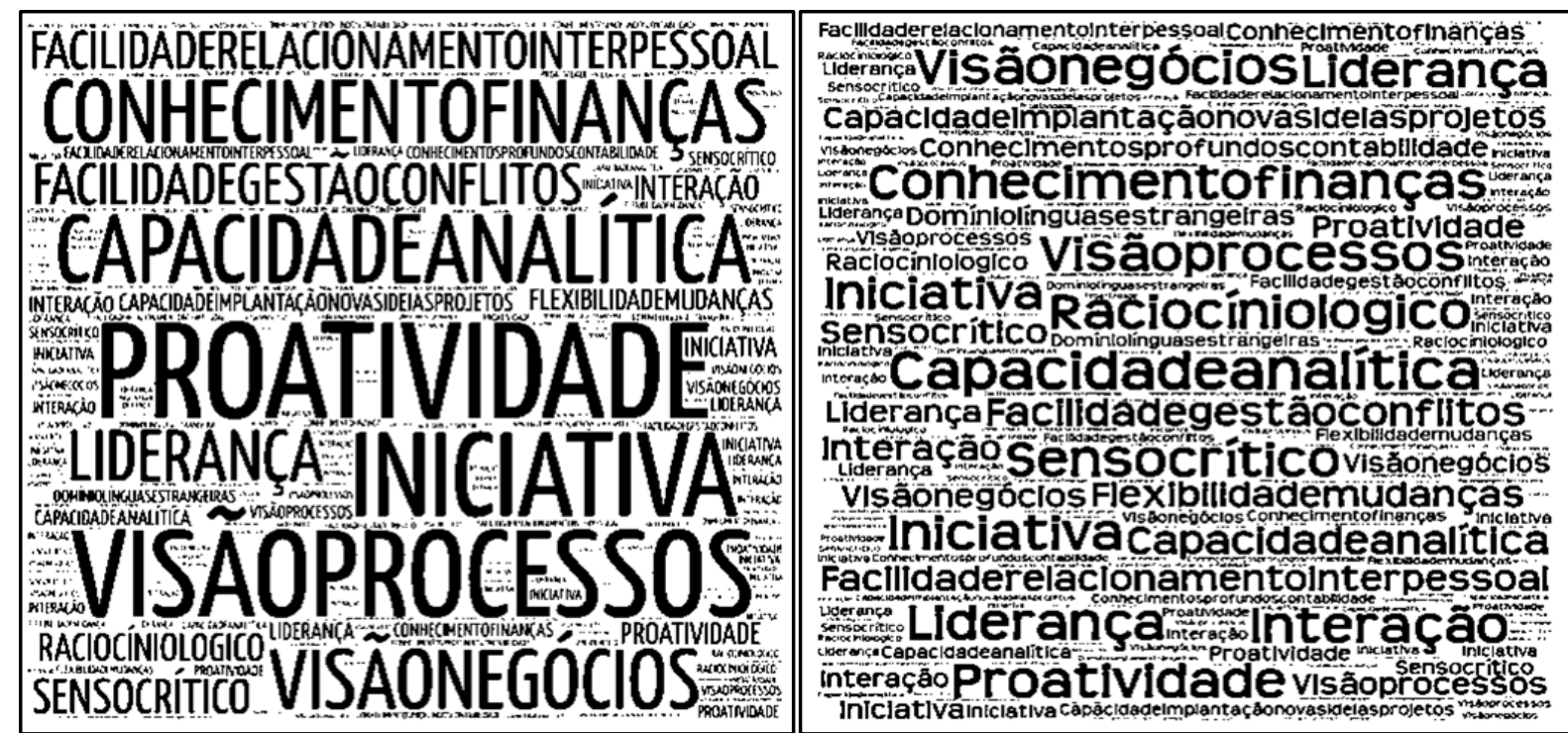

Figura 1. Habilidade requeridas para o cargo de controller

Fonte: Dados da pesquisa.

Conforme evidenciado na Figura 1, observa-se algumas diferenças nas respostas entre as mulheres e os homens. Os requisitos evidenciados apresentam-se em consonância com os observados no estudo de Wiggers et al. (2015). Destaca-se que as mulheres enumeram como habilidades principais para o desempenho do cargo de controller a proatividade, iniciativa e visão de processos, seguido de outras também relatadas como importantes, como conhecimento de finanças, capacidade analítica, visão de negócios e liderança. Em contraponto, os homens relatam como principal habilidade a capacidade analítica, seguido de outras habilidades também mencionadas pelas mulheres como liderança, visão de negócios, proatividade, conhecimento de finanças, entre outros. No geral, mulheres e homens, em certa medida, possuem opiniões distintas em relação as principais habilidades requeridas na profissão de controller, entretanto, ambos os grupos citam que o profissional deve possuir várias habilidades.

No que tange as funções desempenhadas pelo profissional, a Figura 2 mostra as nuvens de palavras que foram elencadas pelos profissionais. As nuvens referem-se a respostas das mulheres e homens, respectivamente. 

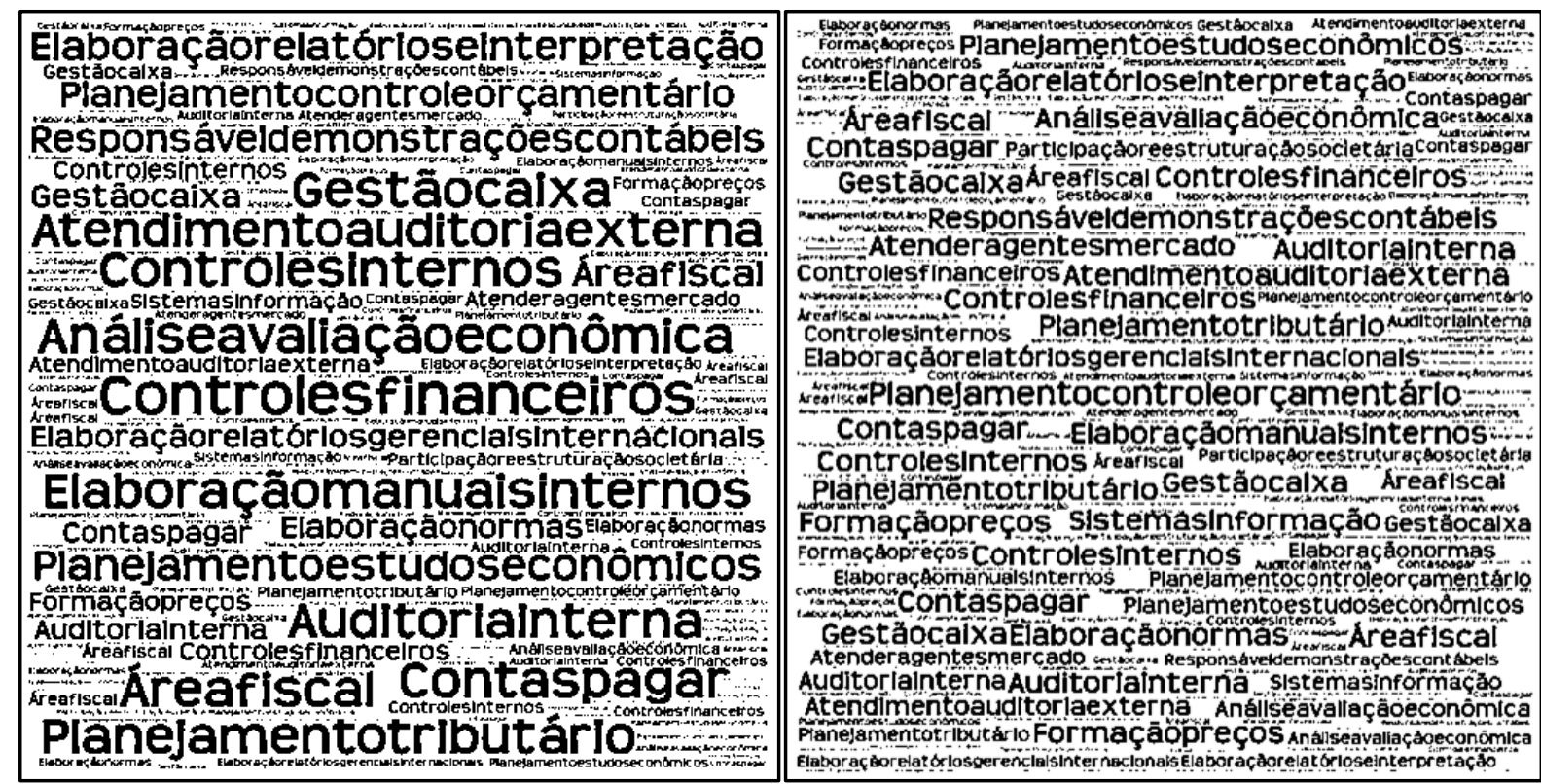

Figura 2. Funções desempenhadas pelo profissional controller

Fonte: Dados da pesquisa.

A Figura 2, também apresenta disparidade entre as respostas das mulheres e dos homens, quanto as funções desempenhadas pelo profissional. Conforme evidenciado, as mulheres mencionam como principais funções o controle financeiro o que é condizente com o relatado anteriormente, quando elas citam como uma habilidade importante o conhecimento em finanças, da mesma forma observa-se várias funções citadas, o que sugere que de fato o profissional deve ser proativo. Tratando-se dos homens, estes também relataram várias funções, sendo que se destacam o planejamento e o controle orçamentário, função que está de acordo com a capacidade analítica, principal habilidade citada por esse grupo. As funções descritas pelos respondentes corroboram com o estudo de Weber (2011) o qual relatou que os controllers desempenham várias funções, sendo o responsável por fornecer informações para administração.

A diversidade de habilidades e funções requeridas e desempenhadas pelo profissional controller evidenciadas no presente estudo pode estar associada também ao porte da empresa e segmento de atuação. Justifica-se pois, a amostra apresentou-se diversificada em relação a esses aspectos e conforme Gomes et al. (2014), as empresas possuem diferentes exigências para contratação de profissionais controllers, as quais variam de acordo com características dela. Os resultados estão alinhados com outras pesquisas, Haussmann et al. (2018), Bernd et al. (2017) e Brighenti et al. (2015) pois também indicam a existência de desigualdade salarial entre homens e mulheres que ocupam a mesma função, no caso, controller. Verificou-se que apesar de ambos os grupos possuírem qualificação semelhante, constatada por meio do teste de médias, a diferença entre salários ainda persiste, sendo que o sexo masculino tem maiores remunerações. Embora, essa diferença salarial possa estar relacionada com a experiência (medida pela idade).

Em síntese os dados quantitativos obtidos neste estudo, permitem inferir que a desigualdade salarial entre homens e mulheres que desempenham a função de controller, no contexto analisado, também se estende para a atividade de controller. Esse achado corrobora com os estudos de Cambota e Pontes (2007), Haussmann et al. (2018), Bernd et al. (2017) e Brighenti et al. (2015).

$\mathrm{Na}$ sequência, por meio de uma análise qualitativa, evidencia-se a percepção dos entrevistados sobre a temática. O roteiro levou o/a (s) respondentes a refletirem sobre as diferenças de gêneros no mercado de trabalho, mais especificamente a desigualdade salarial. Foram entrevistados dois homens, sendo que ambos atuam como controller e duas mulheres, que atuam como account controller e controller. Com a finalidade de preservar a identidade do/a (s) respondentes, foram adotados nomes fictícios. Para as mulheres Terra e Lua e para os homens Sol 
e Mar. As entrevistas discorreram sobre situações do cotidiano de homens e mulheres profissionais controllers. Inicialmente foi questionado aos entrevistados como eles conciliam o trabalho e atividades extras, como reuniões de negócios e jantares com as demandas da família, uma entrevistada relatou que:

Nos dias de hoje esses momentos extrafamiliares são inevitáveis. Costumo ter bastante diálogo com a minha filha e meu marido, e procuro mostrar-lhes a necessidade de abdicar de alguns momentos com eles, em prol do sustento da casa. Acredito que difundir uma cultura de compreensão na família é o melhor caminho. E sendo assim, não digo que apenas "Eu" concilio, mas, todos os membros. O momento é partilhado. [Terra]

Em consonância, a entrevistada Lua também relatou a preocupação em relação ao filho, sobre a comunicação e a divisão de tarefas no ambiente familiar. $\mathrm{O}$ discurso das entrevistadas apresenta-se em consonância com o estudo de Whiting \& Wright (2001), os quais relataram que as mulheres consideram as responsabilidades familiares ao ingressar no trabalho e buscam horários de trabalho compatíveis com as demandas domésticas e da educação dos filhos. Tratando-se dos homens, ambos relataram que conseguem conciliar as atividades extras com as demandas da família, entretanto não se percebeu a mesma preocupação citada pelas mulheres em relação aos filhos, onde Lua relatou: "Organizo quem poderá ficar com meu filho. Verifico a disponibilidade das avós. As outras demandas divido com o esposo". Nesse ponto, uma ilustração (Figura 3) 'tuitada' em fevereiro de 2019 por Anand Mahindra, considerado pela Fortune como um dos 50 maiores líderes do mundo, contribui para demonstrar o que está implícito no discurso das mulheres e homens no que diz respeito a conciliar trabalho e família.

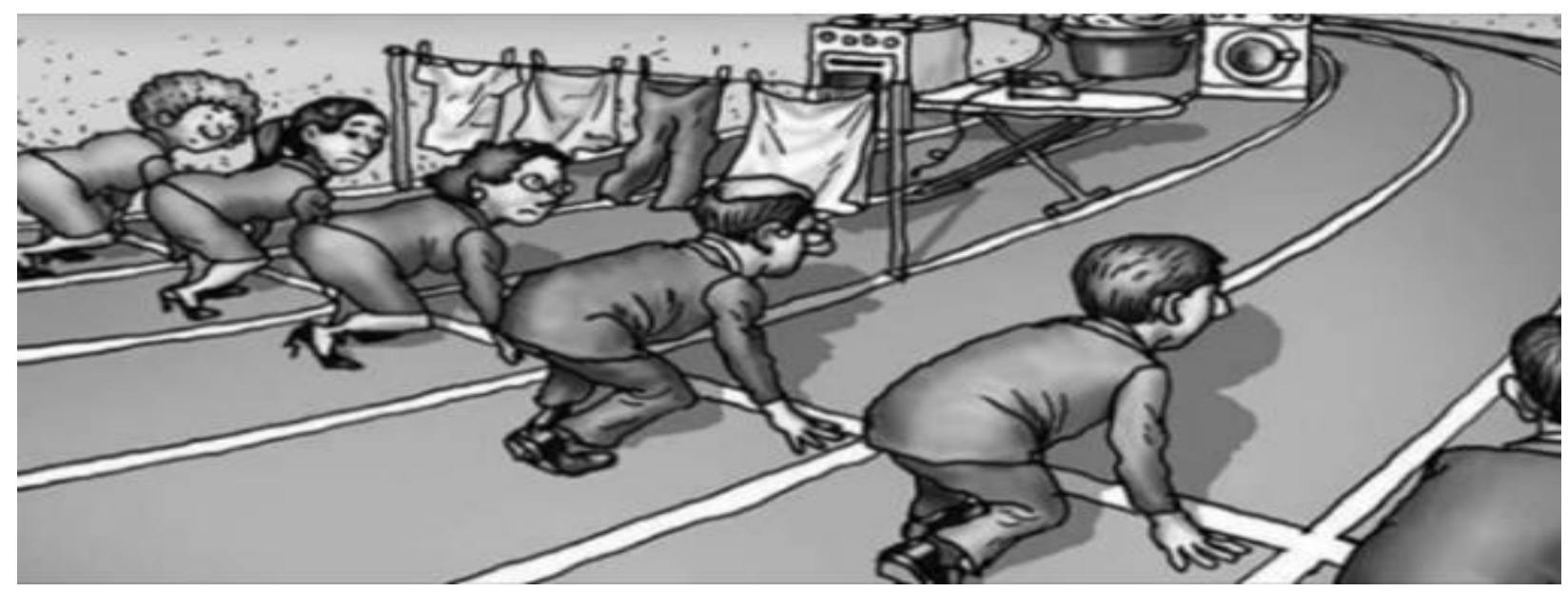

Figura 3. Figura postada por Anand Mahindra

Fonte: Mahindra (2019).

A imagem, embora seja decorrente de uma experiência ocorrida em um contexto diferente do analisado, é oportuna pois possibilita ilustrar o cotidiano presente na fala dos entrevistados.

Por sua vez, ao questionar as mulheres sobre as dificuldades no exercício da profissão, em relação a carga horária, assédio sexual e diferença salarial, Terra relatou dificuldades em relação à diferença salarial e citou a cultura empresarial como um fator dificultador. Lua mencionou ter passado por todas as dificuldades para o exercício da profissão no ambiente de trabalho, especificamente, sobre situação de assédio sexual, Lua comenta: "Já levei algumas cantadas, mais nada que fuja ao machismo diário". Entretanto, a Lua relatou que esses fatores não são empecilhos para o exercício da profissão. Na fala "nada que fuja ao machismo diário" está implícita a resignação da profissional, o 'conformismo', como se o assédio fosse algo inerente à rotina de trabalho. 
Sol e Mar foram questionados quanto ao relacionamento com colegas do sexo oposto no exercício da profissão. Ambos respondentes do sexo masculino declararam não possuir dificuldades no ambiente de trabalho, em relação às atividades e convívio com colegas do sexo oposto. Na sequência, questionou-se sobre a desigualdade salarial entre homens e mulheres que exercem cargos iguais ou equivalentes e os motivos para tal desigualdade. Lua afirmou que existe diferença salarial. Em conformidade, sobre a desigualdade salarial, Terra relatou:

Infelizmente, isso a nível mundial, ainda existe um certo tabu em relação aos salários pagos a homens e a mulheres. Conseguimos evoluir muito pouco com relação ao tema. Acredito que a mulher ainda é vista como o "sexo mais frágil" e por isso, se torna menos bem paga.

Nesse contexto, Araújo \& Ribeiro (2001) declaram que indivíduos podem não ser avaliados pela sua produção e eficiência, mas por características pessoais como gênero. Dessa forma, observa-se a presença de discriminação de gênero na sociedade, a qual pode ser visualizada no mercado de trabalho.

Sol e Mar também foram questionados em relação à desigualdade salarial. Ambos acreditam que na empresa onde trabalham, não existe discriminação salarial em relação ao gênero dos colaborados. Sol mencionou: "Na empresa onde atuo não acredito que exista desigualdade em função do gênero do funcionário ou funcionária".

Quanto à organização em que os entrevistados trabalham, foram realizados alguns questionamentos. As perguntas tiveram como finalidade evidenciar o papel da empresa em relação a desigualdades entre homens e mulheres, mais especificamente, a desigualdade salarial entre sexos no cargo de controller.

Ambas as entrevistadas do sexo feminino relataram que as empresas na qual exercem o cargo de controller, não desenvolvem políticas para estimular a diversidade de gênero e equidade entre os sexos, assim como também não desenvolvem políticas para combater as diferentes formas de preconceito. Da mesma forma, foi mencionado que as empresas não possuem critérios estabelecidos e claros para promoções de colaboradores.

Sol, quando questionado se sua empresa desenvolve políticas para estimular a diversidade de gênero, relatou:

Sim. Temos um comitê de diversidade (sou um dos membros) e atuamos fortemente para estimular a diversidade e estabelecendo ações que representem diferentes perspectivas e experiências aos funcionários potencializando aspectos de diversidade que gerem sucesso ao negócio e um ambiente de trabalho respeitoso e inclusivo. Entre as ações que já realizamos estão: grupos de discussões para saber o que os demais funcionários entendem por diversidade e quais pontos a empresa poderia melhorar, coral da diversidade com mais de 30 funcionários participantes, semana da diversidade abordando temas diversos como portadores de necessidades especiais; empoderamento feminino; workshops além de painéis e palestras.

Mar declarou que a empresa na qual atua não há no momento políticas voltadas a esses aspectos, entretanto citou: "Mas várias ações de RH são voltadas ao público feminino como a Campanha contra o câncer de mama e celebração do dia das mães". Dessa forma, por meio do discurso dos agentes, percebeu-se respostas divergentes em relação a políticas para estimular a diversidade de gênero, de um lado observa-se que nada é feito e do outro existem políticas e iniciativas em prol da diversidade de gêneros.

Quanto aos critérios para um colaborador conseguir uma promoção, Mar relatou não existir na empresa em que atua critérios claros. Porém, Sol mencionou que há critérios claros:

As promoções são baseadas no desempenho individual de cada colaborador, semestralmente metas e objetivos são discutidos e alinhados e na maioria dos casos as promoções baseiam-se na performance individual e colaboração para os resultados coletivos. 
Ao resgatar a Figura 1, a fala acima ganha outra dimensão, como comparar performances individuais distintas? Quais colaboradores são potencialmente mais promissores para a organização?

Em relação ao ambiente de trabalho foi questionado se a caracterização, a organização, a decoração do ambiente, as cores e a disposição de móveis está constituída da forma que mais lhes agrada. As mulheres responderam que o ambiente não é caracterizado de acordo com as escolhas delas e da forma como se sentem mais confortáveis, Terra relatou: "A empresa é organizada e decorada de maneira neutra e eu não caracterizo o ambiente da forma que me sinto mais confortável". Sol relatou não ter o hábito de caracterizar o escritório, Mar declarou: "O ambiente em que trabalho é sóbrio devido ao perfil de cliente que atendemos, e isso não me incomoda".

Ainda em relação ao ambiente de trabalho, foi perguntado aos entrevistados se existe a preferência por trabalhar com homens ou mulheres, ou não existe a importância quanto ao sexo biológico ou expressão de gênero. Lua relatou que não possui preferência e não se importa quanto ao sexo ou expressão de gênero. Porém, em discordância, Terra mencionou:

Particularmente, prefiro trabalhar com homens. Acredito que são mais compreensivos quando o assunto são mulheres e assim, as relações profissionais estabelecidas, acabam facilitando os trabalhos.

Tratando-se dessa questão, ambos os homens relataram não ter preferência em trabalhar com homens ou mulheres. Sol destaca: "Não tenho preferência e não acredito que sexo ou gênero podem contribuir para uma melhor performance profissional". Entretanto, nessa linha, conforme Hofstede (1991), em uma sociedade com alto índice de masculinidade há uma valorização do sucesso e do progresso material, onde há uma competição entre os colaboradores, em contraponto, ao verificar um alto índice de feminilidade, há a valorização da igualdade, solidariedade e da qualidade de vida. Assim, verifica-se que na percepção dos homens o sexo não influencia no desempenho das atividades do profissional.

Destaca-se que a discriminação de gênero pode ser percebida na profissão de controller, por meio das dificuldades em relação ao exercício da profissão, que envolvem aspectos como, carga horário e assédio sexual. Além disso, a desigualdade salarial entre homens e mulheres, no contexto analisado, além de ter sido evidenciada pelos testes estatísticos realizados e estarem em consonância com os estudos de Haussmann et al. (2018), Bernd et al. (2017) e Brighenti et al. (2015), os quais envolveram outras funções inerentes à contabilidade, foi igualmente evidenciada no discurso analisados. Isso indica que a desigualdade salarial não é velada, ou seja, as mulheres têm consciência do fato. E ainda, conforme Carrieri, Diniz, Souza e Menezes (2013), ao se investigar questões de gênero relacionadas às qualidades específicas de mulheres em cargos executivos, há pontos positivos e negativos quanto ao exercício da função, como por exemplo, os dilemas quanto à sensibilidade, aos conflitos relacionados ao poder de sedução, ao preconceito e à violência contra mulheres no exercício de sua função e também à maternidade. Fatores que também foram evidenciados no presente estudo e que corroboram com as perspectivas analisadas.

As práticas discriminatórias também podem ser observadas, quando identificada a falta de políticas organizacionais para estimular a diversidade de gênero. Entretanto, quanto a esse aspecto, as respostas foram distintas, pois, evidenciou-se práticas realizadas por algumas empresas com a finalidade de estimular a diversidade e consequentemente a inserção das mulheres no mercado.

A falta de critérios claros para promoções nas empresas, também constitui-se como um aspecto de discriminação, sendo que o gênero pode influenciar em tal decisão quando não são abordados critérios claros, que sejam do conhecimento de todos os colaboradores, essa evidência é condizente com o estudo de Cavazotte, Oliveira e Miranda (2010), que relataram a desigualdade em relação a critérios de recompensa. 
Em síntese, a análise dos dados obtidos na presente pesquisa, quantitativos e qualitativos, permitem inferir que a discriminação salarial de gênero na profissão de controller persiste, assim como a existência de outros aspectos de discriminação de gênero percebidos pelos agentes. Entretanto, observou-se que em alguns ambientes organizacionais políticas e ações para estimular a diversidade de gênero estão sendo realizadas.

\section{CONCLUSÃO}

Este estudo objetivou evidenciar aspectos de desigualdade de gênero na atuação de controllers e descrever, por meio do discurso dos agentes, como estes percebem as práticas discriminatórias. Para tanto realizou-se uma pesquisa exploratória, descritiva e quali-quantitativa. Dessa forma, foram enviados questionários via rede de contatos profissional LinkedIn ${ }^{\circledR} \mathrm{e}$ realizadas entrevistas com profissionais através do software Skype. Um total de 135 profissionais responderam ao questionário, sendo 83 homens e 52 mulheres. Foram entrevistados quatro profissionais, sendo dois homens e duas mulheres.

Os resultados evidenciaram existência de desigualdade salarial entre homens e mulheres para a profissão controllers. No contexto analisado os resultados da análise estatística mostraram que mulheres possuem remuneração inferior aos homens no cargo de controller. Verifica-se que o grupo do sexo masculino, em média, possui remuneração entre 10 e 12 salários mínimos, diferente do grupo feminino, o qual a média corresponde a uma remuneração entre sete e nove salários mínimos.

Os dados obtidos pelas entrevistas confirmaram que a discriminação de gênero pode ser percebida na profissão de controller, por meio das dificuldades em relação ao exercício da profissão, que envolvem aspectos como, carga horária e assédio sexual. As práticas discriminatórias também podem ser observadas, quando identificada a falta de políticas organizacionais para estimular a diversidade de gênero, a falta de critérios claros para promoções nas empresas, sendo que o gênero pode influenciar em tal decisão quando não são abordados critérios claros, que sejam do conhecimento de todos os colaboradores.

O presente estudo traz como contribuição para literatura que envolve a temática, pois utilizou uma abordagem mista para investigar a discriminação salarial na profissão de controller. Os achados aqui descritos podem oferecer insights para as empresas despenderem maior atenção aos profissionais e promover ações que garantam maior equidade. Ressalta-se ainda, atenção dada a profissão de controller, no que se refere à atuação feminina. Nessa, destaca-se o ambiente que historicamente é marcado pela atuação masculina, onde mulheres eram vistas apenas em afazeres domésticos, mas, atualmente, há um crescente aumento da participação feminina na profissão.

Assim, sob a perspectiva de uma reflexão quanto ao discurso dos entrevistados, percebeuse que os homens são mais diretos quanto ao que lhes foi questionado e menos discursivos em comparação às mulheres. Desse modo, o discurso das mulheres parece mais engajado no que se refere à percepção de desigualdade. Outra percepção refere-se à família, sendo que as mulheres se mostraram mais preocupadas com os filhos e com a conciliação entre família e trabalho. Entretanto, nas entrevistas, os quatro participantes foram tratados da mesma forma, e notou-se que as mulheres sentem-se e estão mais vulneráveis a discriminações no trabalho, no que se refere às dificuldades no exercício de sua função quando comparadas aos homens.

Como limitação, pode-se observar a população escolhida, o cenário brasileiro, sendo que este pode apresentar características distintas, não permitindo generalizar os resultados para outros contextos. Outra limitação refere-se à quantidade de entrevistados, sendo que os resultados se aplicam somente ao contexto da pesquisa. Para pesquisas futuras sugere-se ampliar o contexto estudado e verificar se em outros contextos há desigualdade salarial e, quando comparados, o quanto essa desigualdade representa, além de entrevistas com mais profissionais a fim de comparação, inclusive entre empresas com ramos de atividades distintas, ou semelhantes. Ainda, pesquisas futuras também podem realizar experimentos com homens e mulheres controllers para 
a evidenciação da percepção deles sobre o tema frente a colegas de sexos opostos. Todavia, observa-se a área estudada como promissora para pesquisas a serem desenvolvidas, no cenário nacional e internacional, para ampliação e confirmação dos resultados aqui evidenciados.

\section{REFERÊNCIAS}

Araújo, V. F., \& Ribeiro, E. P. (2001). Diferenciais de salários por gênero no Brasil: uma análise regional. Universidade Federal do Rio Grande do Sul, Programa de Pós-Graduação em Economia.

Bauer, M. W., \& Gaskell, G. (2015). Pesquisa Qualitativa, com Texto, Imagem e Som: um manual prático. (Vol. 1, 13a ed.). Petrópolis, RJ: Editora Vozes.

Bernd, D. C., Anzilago, M., \& Beuren, I. M. (2017). Presença do Gênero Feminino entre os Discentes dos Programas de Pós-Graduação de Ciências Contábeis no Brasil. Revista de Educação e Pesquisa em Contabilidade (REPeC), 11(4).

Blau, F. D., \& Kahn, L. M. (1994). Rising wage inequality and the US gender gap. The American Economic Review, 84(2), 23-28.

Bradley, H. (1999). Gender and power in the workplace: Analysing the impact of economic change. Basingstoke: Macmillan.

Brighenti, J., Jacomossi, F., \& da Silva, M. Z. (2015). Desigualdades de gênero na atuação de contadores e auditores no mercado de trabalho catarinense. Enfoque: Reflexão Contábil, 34(2), 109-122.

Broadbent, J., \& Kirkham, L. (2008). Glass ceilings, glass cliffs or new worlds? Revisiting gender and accounting. Accounting, Auditing \& Accountability Journal, 21(4), 465-473.

Burke, M. D. R. J. (1994). Women in management: Current research issues. Sage.

Cambota, J. N., \& Pontes, P. A. (2007). Desigualdade de rendimentos por gênero intraocupações no Brasil, em 2004. Revista de economia contemporânea, 11(2), 331-350.

Carnegie, G. D., \& Lehman, C. (2012). We've come a long way! Maybe! Re-imagining gender and accounting. Accounting, Auditing \& Accountability Journal, 25(2), 256-294.

Carrieri, A. D. P., Diniz, A. P. R., Souza, E. M. D., \& Menezes, R. S. S. (2013). Gender and work: representations of femininities and masculinities in the view of women Brazilian executives. BAR-Brazilian Administration Review, 10(3), 281-303.

Cavazotte, F. D. S. C. N., Oliveira, L. B. de, \& Miranda, L. C. de (2010). Desigualdade de gênero no trabalho: reflexos nas atitudes das mulheres e em sua intenção de deixar a empresa. Revista de Administração-RAUSP, 45(1).

Conselho Federal de Contabilidade (2019). Estatísticas. Recuperado de https://cfc.org.br/fiscalizacao-etica-e-disciplina/estatisticas/ 
Dal Magro, C. B., Carpes, A. D., Vergini, D., \& Silva, M. Z. (2018). Glass ceiling em cargos de board e seu impacto no desempenho organizacional. Revista Contemporânea de Contabilidade, 15(34), 158-180.

Dambrin, C., \& Lambert, C. (2012). Who is she and who are we? A reflexive journey in research into the rarity of women in the highest ranks of accountancy. Critical Perspectives on Accounting, 23(1), 1-16.

Dwyer, P. D., \& Roberts, R. W. (2004). The contemporary gender agenda of the US public accounting profession: embracing feminism or maintaining empire? Critical Perspectives on Accounting, 15(1), 159-177.

Farjaudon, A. L., \& Morales, J. (2013). In search of consensus: The role of accounting in the definition and reproduction of dominant interests. Critical Perspectives on Accounting, 24(2), 154-171.

Flynn, A., Earlie, E. K., \& Cross, C. (2015). Gender equality in the accounting profession: one size fits all. Gender in Management: An International Journal, 30(6), 479-499.

Gomes, C. V., de Souza, P., \& Lunkes, R. J. (2014). El perfil profesional de controlar impulsada por las empresas brasileñas. Revista de Globalización, Competitividad y Gobernabilidad, 8(1), 34.

Guerreiro, R., Frezatti, F., \& Casado, T. (2006). Em busca de um melhor entendimento da contabilidade gerencial através da integração de conceitos da psicologia, cultura organizacional e teoria institucional. Revista Contabilidade \& Finanças-USP, 17.

Haussmann, D. C. S., Vogt, M., Nelson, H., \& da Silva, M. Z. (2018). Desigualdades de gênero no mercado de trabalho brasileiro: uma análise na área de ciências sociais aplicadas. Enfoque, $37(3), 129$.

Haynes, K. (2013). Sexuality and sexual symbolism as processes of gendered identity formation: An autoethnography of an accounting firm. Accounting, Auditing \& Accountability Journal, 26(3), 374-398.

Haynes, K. (2017). Accounting as gendering and gendered: A review of 25 years of critical accounting research on gender. Critical Perspectives on Accounting, 43, 110-124.

Hofstede, G. (1991). Cultures and organizations. Intercultural cooperation and its importance for survival. Software of the mind. London: McGraw-Hill.

Kirkham, L. M. (1992). Integrating herstory and history in accountancy. Accounting, Organizations and Society, 17(3-4), 287-297.

Kirkham, L. M., \& Loft, A. (1993). Gender and the construction of the professional accountant. Accounting, Organizations and Society, 18(6), 507-558.

Král, B., Mikołajewicz, G., Šoljaková, L., \& Nowicki, J. (2017). Professional Competences of Controllers: The Case of Poland. European Financial and Accounting Journal, 2017(2), 17-40. 
Lehman, C. R. (1992). "Herstory" in accounting: The first eighty years. Accounting, Organizations and Society, 17(3-4), 261-285.

Lunkes, R. J., Schnorrenberger, D., Gasparetto, V., \& Vicente, E. F. R. (2009). The controllership functions in the united states, Germany and Brazil. Revista Universo Contabil, 5(4), 63.

Madalozzo, R. (2010). Occupational segregation and the gender wage gap in Brazil: an empirical analysis. Economia aplicada, 14(2), 147-168.

Mahindra, A. (2019). Recuperado em fevereiro, 2019, de https://twitter.com/anandmahindra/status/1092675489586569216?ref_src=twsrc\%5Etfw\%7Ct wcamp\%5Etweetembed\%7Ctwterm\%5E1092675489586569216\&ref_url=https\%3A\%2F\%2F www.criatives.com.br\%2F2019\%2F03\%2Fbilionario-indiano-faz-publicacao-sobre-otrabalho-das-mulheres-sem-reconhecimento-e-viraliza-na-internet $\% 2 \mathrm{~F}$

Marlow, S., \& Carter, S. (2004). Accounting for change: Professional status, gender disadvantage and self-employment. Women in Management Review, 19(1), 5-17.

Montano, J. L. A., Donoso, J. A., Hassall, T., \& Joyce, J. (2001). Vocational skills in the accounting professional profile: the Chartered Institute of Management Accountants (CIMA) employers' opinion. Accounting Education, 10(3), 299-313.

Oro, I. M., Beuren, I. M., \& Carpes, A. M. S. (2013). Competências e habilidades exigidas do controller e a proposição para sua formação acadêmica. Contabilidade Vista \& Revista, 24(1).

Pettit, B., \& Hook, J. (2002). The structure of women's employment in comparative perspective. Social Forces, 84(2), 779-801.

Silva, S. M. C. D. (2016). Tetos de vitrais: gênero e raça na contabilidade no Brasil. Tese de Doutorado, Universidade de São Paulo, São Paulo, SP, Brasil.

Scott, A. J. (1987). The semiconductor industry in South-East Asia: Organization, location and the international division of labour. Regional Studies, 21(2), 143-159.

Young, J. J. (2013). (En) gendering sustainability. Critical Perspectives on Accounting, 26, 67-75.

Weber, J. (2011). The development of controller tasks: explaining the nature of controllership and its changes. Journal of Management Control, 22(1), 25-46.

Whiting, R. H., \& Wright, C. (2001). Explaining gender inequity in the New Zealand accounting profession. The British Accounting Review, 33(2), 191-222.

Wiggers, N., Lunkes, R. J., \& de Souza, P. (2015). Controller: estudo sobre a relação entre funções, salário e formação acadêmica. Enfoque: Reflexão Contábil, 34(2), 1-14.

Zoni, L., \& Kenneth, M. (2007). Controller involvement in management: an empirical study in large Italian corporations. Journal of Accounting \& Organizational Change, 3(1), 29-42. 


\section{Apêndice 1}

Roteiro das entrevistas

1. No seu trabalho, ao ser convidado a participar de eventos, reuniões de negócios, atividades extra, jantares e capacitações fora do horário de trabalho, como você concilia essas atividades com as demandas da família?

2. Você sente algum tipo de dificuldade para o exercício da sua profissão? No que tange a alta carga; assédio sexual; conciliação da família com trabalho; diferença salarial.

3. Alguma vez, em sua trajetória profissional já se deparou com alguma situação de assédio sexual? Pode comentar sobre?

4. Você acredita que há desigualdade salarial entre homens e mulheres que exercem cargos iguais ou equivalentes na sua organização? Por quais motivos?

5. A sua empresa desenvolve políticas para estimular a diversidade de gênero e equidade entre os sexos, assim como combater diferentes formas de preconceito? Se sim, como são essas políticas, poderia citar exemplos?

6. Na sua organização, para um colaborador conseguir uma promoção, há critérios claros para que ele seja selecionado, ou simplesmente comunicado? Como ocorre esse processo?

7. Particularmente, você prefere trabalhar com homens, mulheres, ou não se importa quanto ao sexo biológico ou expressão de gênero. Você acredita que isso pode interferir no desenvolvimento do seu trabalho?

8. No seu ambiente de trabalho, você o caracteriza (organização, decoração do ambiente, cores, disposição de móveis) como se sente mais confortável? E isso incomoda algum colega? 